\title{
МЕТОДОЛОГИЯ ФОРМИРОВАНИЯ СИСТЕМЫ ПРОИЗВОДСТВЕННОГО МЕНЕДЖМЕНТА
}

\section{(C) 2019 Забелин Борис Фёдорович}

кандидат экономических наук,

Институт промышленного менеджмента, экономики и торговли (ИПМЭиТ)

Санкт-Петербургский политехнический университет Петра Великого (СПбПУ), Россия, Санкт-Петербург

E-mail: zabelinbf@mail.ru

\section{(c) 2019 Конников Евгений Александрович}

Институт промышленного менеджмента, экономики и торговли (ИПМЭиТ)

Санкт-Петербургский политехнический университет Петра Великого (СПбПУ), Россия, Санкт-Петербург

E-mail: konnikov.evgeniy@gmail.com

\section{(c) 2019 Никишин Вадим Михайлович}

кандидат экономических наук, доцент

Санкт-Петербургский государственный электротехнический университет «ЛЭТИ» им. В.И. Ульянова (Ленина), Россия, Санкт-Петербург

\section{(c) 2019 Хатанзейский Константин Кимович}

кандидат философских наук, кафедра «Реклама и связи с общественностью»

Санкт-Петербургский политехнический университет Петра Великого (СПбПУ),

Россия, Санкт-Петербург

E-mail: hatanzkk@mail.ru

В статье рассмотрена современная концепция формирования эффективно функционирующей системы производственного менеджмента. Отмечается, что система производственного менеджмента, занимая центральное место, активно взаимодействует по прямой и обратной связи с такими основными системами, как стратегический менеджмент, прогнозирование развития фирмы, управление стоимостью продукции предприятия. Перспективы развития систем производственного менеджмента в новом веке будут состоять в применении более сложных форм управления с внедрением новых технологических и технических инноваций. В основе новой стратегии управления производством реализуется идея создания производственных систем, работающих в режиме конвейера нововведений.

Ключевые слова: система производственного менеджмента, стратегический менеджмент, конвейер нововведений, конкурентоспособность.

Потенциальные и реальные успехи в реформировании российской экономики, обусловленные становлением рыночных отношений, во многом зависят от масштабов использования современных систем производственного менеджмента. Обеспечение высокой эффективности применяемых систем производственного менеджмента на предприятиях различных отраслей промышленности является одним из основных факторов достижения ими достаточно высокого уровня конкурентоспособности, динамичного развития, устойчивого и долговременного присутствия на целевом рынке, а также по- вышения благосостояния своих акционеров.

Менеджмент можно рассматривать как целостный комплекс управленческих подсистем, позволяющих координировать деятельность внутренней среды производства, используя многообразие ее ресурсов в условиях динамических изменений во внешней среде [1].

Ряд ученых экономистов и практиков управления определяют менеджмент как искусство, которому можно научиться только как ремеслу посредством практического опыта при наличии интуитивных способностей и таланта к управленческой деятельности [2]. 
Среди основных разновидностей менеджмента (стратегический, финансовый, инвестиционный, информационный, венчурный, оценки стоимости бизнеса, реинжиниринга бизнес-процессов) центральное место принадлежит производственному менеджменту. Это обусловлено тем, что указанный вид менеджмента имеет прямое отношение к обеспечению эффективности использования всех необходимых ресурсов (труда, основных средств, капитальных вложений) при производстве готовой продукции, пользующейся спросом у покупателей и к достижению достаточно высокой конкурентоспособности на рынке [3]. Именно от эффективности функционирования систем производственного менеджмента на отечественных предприятиях различных отраслей промышленности во многом зависит успех реализации важнейших народнохозяйственных задач.

Переход отечественных промышленных предприятий к рыночным отношениям, внедрение ранее неизвестных организационных структур правления (холдинговых компаний, финансово-промышленных групп) обусловливает необходимость реализации принципиально нового подхода к построению системы производственного менеджмента. Эта новизна заключается в тесной интеграции основных компонентов системы менеджмента на предприятии, во взаимной целевой и ресурсной увязки (деятельности материнской компании и дочерних фирм, в достаточно широком использовании, так называемого процессного подхода к построению отдельных подсистем и системы менеджмента в целом, в наиболее полном учете требований, обусловленных международными стандартами серии ИСО 9000:2000, а также в обосновании экономической эффективности отдельных бизнес-процессов и системы производственного менеджмента в целом [4].

Перспективы развития систем производственного менеджмента в новом веке будут состоять в применении более сложных форм управления с внедрением новых технологических и технических инноваций. В основе новой стратегии управления производством реализуется идея создания производственных систем, работающих в режиме конвейера нововведений. Суть ее состоит в том, чтобы ориентировать предприятия [5]:

1) на постоянное внедрение новой продукции и быструю поставку вновь созданной про- дукции на целевой рынок;

2) сокращение затрат;

3) использование принципов международного стандарта серии ИСО 9000:2000, при создании новой продукции;

4) снижение цен на выпускаемую продукцию или оказываемые услуги.

Главными направлениями в реализации современной стратегии реализации производственного менеджмента становятся [6]:

- комплексная информатизация и автоматизация производственных процессов;

- использование реинжиниринга при создании форм и методов управления, включая вопросы организации технико-экономической базы;

- непрерывное повышение квалификации как самих работников, так и менеджеров;

- более масштабное использование нетрадиционных форм торговли (в частности посредством сети Интернет).

Х. Хаммер и Дж. Чампи, родоначальники реинжиниринга, определяют его «как фундаментальное переосмысление и радикальное перепроектирование деловых процессов для достижения резких, скачкообразных улучшений в решающих, современных показателях деятельности предприятия таких, как стоимость, качество, сервис».

Вариант построения интегрированной системы менеджмента на предприятии приведен на рис. 1.

Из рис. 1 следует, что система производственного менеджмента, занимая центральное место, активно взаимодействует по прямой и обратной связи с такими основными системами, как стратегический менеджмент, прогнозирование развития фирмы, управление стоимостью продукции предприятия. Любое современное предприятие, желающее добиться стабильного и долговременного присутствия на целевом рынке, должно иметь обоснованный стратегический план своего развития.

Процесс разработки системы стратегического управления включает ряд основных этапов (рис. 2) [7].

Как видим, процесс осуществления стратегического управления на предприятии начинается с формулирования миссии.

Современная концепция построения системы производственного менеджмента, отвечающая одному из главных требований рыночной 


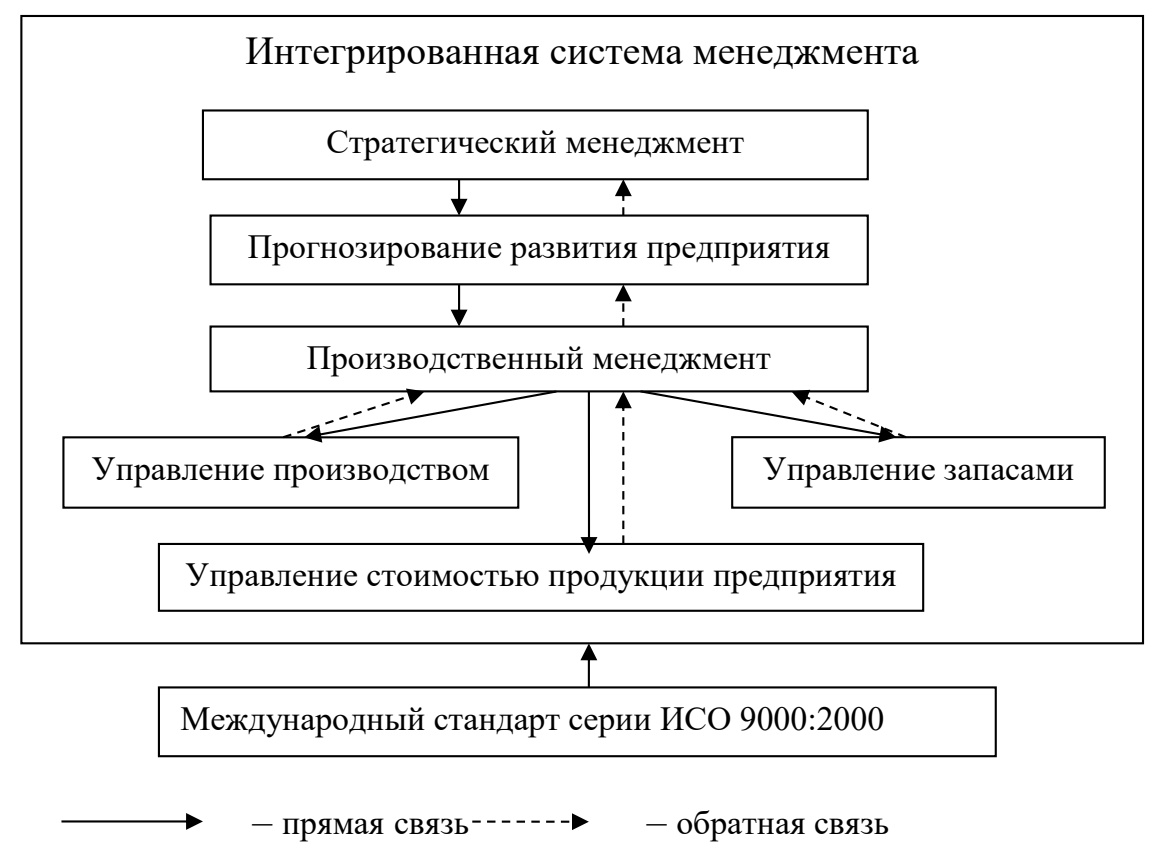

Puc. 1. Интегрированная система производственного менеджмента

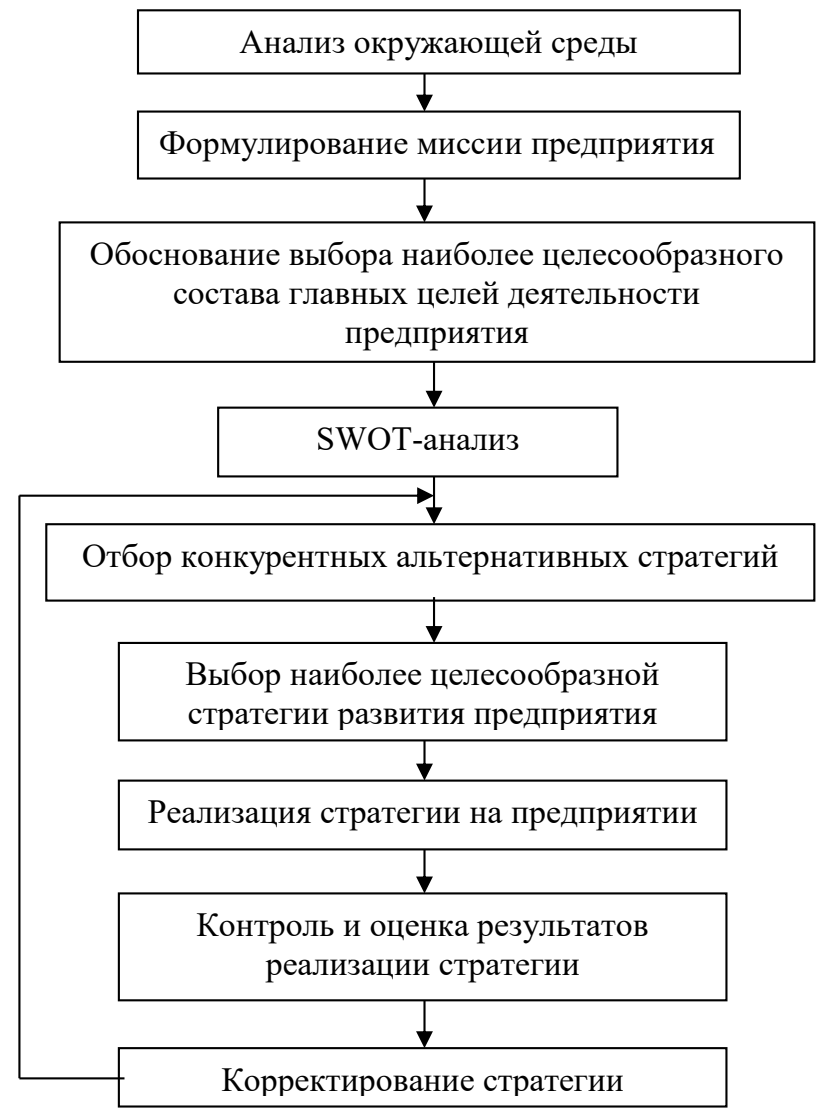

Puc. 2. Основные этапы реализации системы стратегического управления 


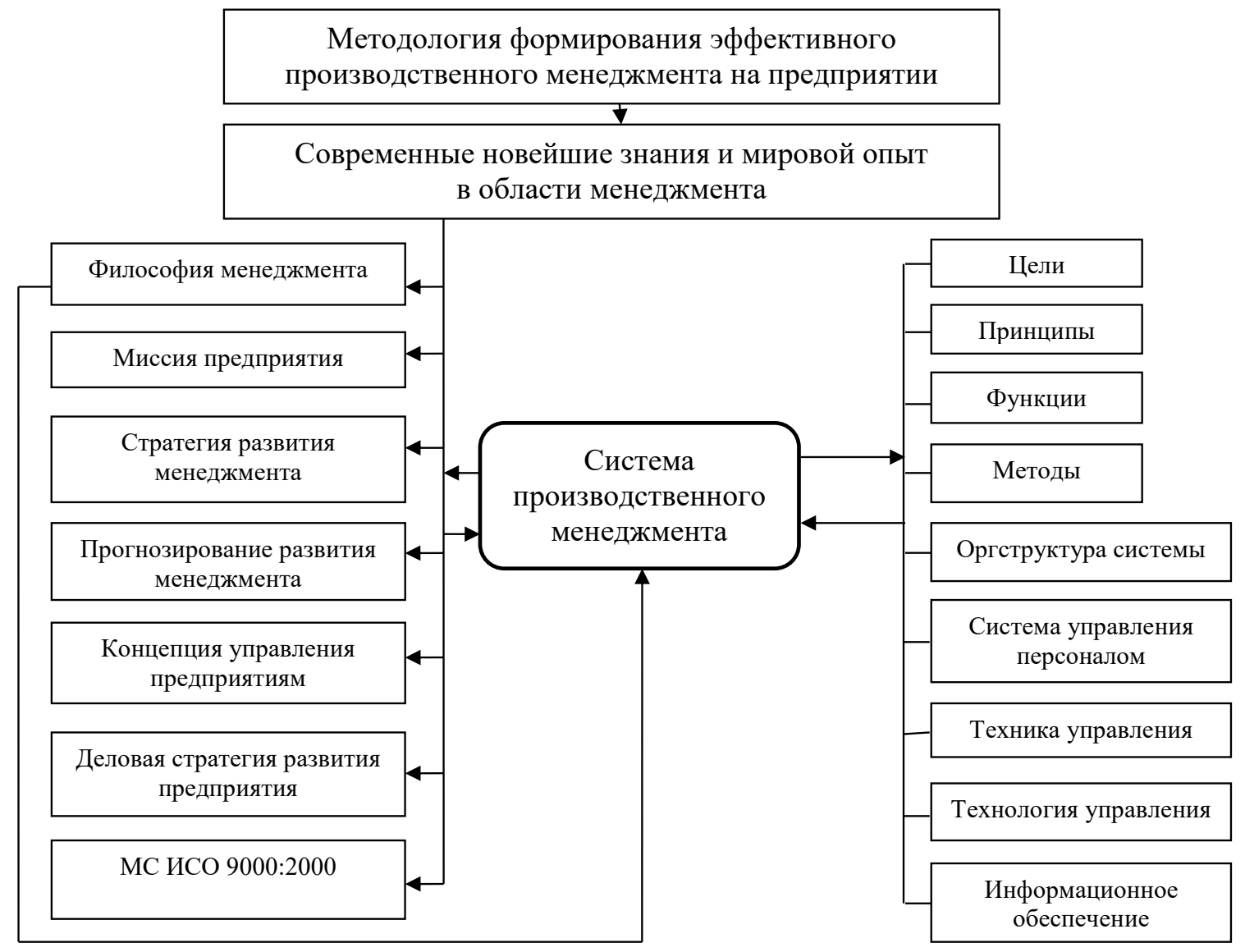

Рuc. 3. Составные элементы теории и методологии построения системы менеджмента предприятия

экономики - быть высоко конкурентоспособным - должна содержать основные компоненты, которые в систематизированном виде приведены на рис. 3.

Таким образом, современная концепция формирования эффективно функционирующей системы производственного менеджмента базироваться на строгом соблюдении этапности работ (разработка стратегии, прогнозирование развития предприятия, проектирование системы производственного менеджмента), наиболее полном учете международных стандартов серии ИСО 9000:2000, реализации принципов построения соответствующих систем, широкое использование методологии реинжиниринга, новых информационных технологий и последних достижений в различных науках [8].

\section{Библиографический список}

1. Барсков В.В., Белостоцкая А.А., Забелин Б. Ф., Конников Е. А. Актуальные вопросы производственного менеджмента в практической деятельности промышленного предприятия. Казань, 2017. 104 с.

2. Багиев Г.Л., Газизуллин Н. Ф. Организация управления ценовой политикой предпринимательских и коммерческих структур в современных условиях // Проблемы современной экономики. 2018. № 2 (66). С. $282-284$.

3. Забелин Б.Ф., Конников Е.А., Погребова О.А. Технология переустройства предприятия как важнейший инструмент адаптации персонала к изменениям на предприятии // Экономика и предпринимательство. 2017. № 8-1 (85). С. 565-568.

4. Конников Е.А., Барсков В.В. Цель российской промышленности и результаты ее достижения на современном этапе // Экономика и предпринимательство. 2015. № 11-2 (64). С. 167-170.

5. Конников Е.А., Конникова О.А., Лукашевич Н. С. Векторная модель оценки потенциальной результативности решений, направленных на повышение устойчивости развития промышленного предприятия // Экономические науки. 2019. № 170. С. 47-50. 
6. Мартынов В.И., Забелин Б.Ф. Механизм хозяйственного поведения предпринимателя // Экономический вектор. 2018. № 3 (14). С. 9-12.

7. Ц Царев В.В. Внутрифирменное планирование.- СПб.: Питер, 2002.- 496 с.

8. Konnikov E.A., Konnikova O.A., Rodionov D.G. Impact of 3d-printing technologies on the transformation of industrial production in the Arctic zone // Resources. 2019. Vol. 8. \#1. P. 1. 